\title{
OPNET Modeler simulations of performance for multi nodes wireless systems
}

\author{
Beata Krupanek* and Ryszard Bogacz \\ Silesian University of Technology, Faculty of Electrical Engineering Institute of Measurement Science, Electronics and Control, \\ Gliwice, Poland
}

Received: 23 December 2015 / Accepted: 9 March 2016

\begin{abstract}
Paper presents a study under the Quality of Service in modern wireless sensor networks. Such a networks are characterized by small amount of data transmitted in fixed periods. Very often this data must by transmitted in real time so data transmission delays should be well known. This article shows multimode network simulated in packet OPNET Modeler. Also nowadays the quality of services is very important especially in multi-nodes systems such a home automation or measurement systems.
\end{abstract}

Keywords: Delays, WiFi, OPNET, Quality of Service

\section{Introduction}

Nowadays, one of the popular wireless technologies, use to transfer different types of data, is the IEEE 802.11 standard. This popular "WiFi" technology provides low-cost wireless Internet capability for end users and also is used in modern measurement and control distributed systems. Wireless medium is a shared medium, so as more and more devices demand the bandwidth, concentrating on performance becomes critical. As the wireless LANs are giving a competition to the Ethernet, apart from speed it will also have to assure the Quality of Service, especially when dealing with voice, video and other real time services.

In this situation, reliable data transport with Quality of Service criteria, related to throughput or latency [1], is needed. To analyze the QoS parameters, especially referring to wireless communication, is not easy because it is affected by a number of parameters like: channel access method, physical and environmental conditions, the number of nodes, distance etc. The WLAN media is error prone and the bit error rate (BER) is very high compared to the BER of wired networks. In addition, Carrier Sensing is difficult in wireless networks because a station is incapable of listening to its own transmissions in order to detect a collision. The Hidden Terminal problem also decreases the performance of a WLAN.

A proper selection of protocols and topology helps in maintaining and improving the QoS support of a wireless network. IEEE 802.11 standard has two sublayers MAC protocols: Distributed coordination function (DCF) and point coordination function (PCF). The DCF supports best effort delivery of packets while the PCF is built on

^ Correspondence: beata.krupanek@polsl.pl the top of DCF and provides services for time-bounded traffic. The 802.11 MAC layer aims to provide access control functions to the wireless medium such as access coordination, addressing or frame check sequence generation.

\section{Quality of services in wireless measurement systems}

The IEEE 802.11 standard for wireless LANs covers the Medium Access Control (MAC) and the physical (PHY) layers. Three different Physical layers specifications exist in the $2.4 \mathrm{GHz}$ range of the unlicensed spectrum, but commonly used hardware is based on the Direct Sequence Spread Spectrum (DSSS) technique. The MAC protocol operates in the DCF and PCF modes. The DCF is the fundamental access method. It uses Carrier Sense Multiple Access with Collision Avoidance (CSMA/CA) for channel access, Request-To-Send and Clear-To-Send (RTS/CTS) messages for reservations and Acknowledgements (ACK) for reliability. The PCF mode is used only in infrastructure networks. It relies on a point coordinator (PC) that resides in the Access Point to perform polling, so that polled stations may have contention-free access to the channel [2].

In this paper is modeled the basic DCF (CSMA/CA) protocol, the DCF protocol with RTS/CTS, and the PCF protocol for medium large office network. Both these mechanisms are not equipped with full-fledged built in system for supporting real time services makes it very difficult to provide the required QoS [3]. The main requirement of IEEE 802.11 WLAN is to guarantee the QoS requirements due to unaware functions such as dedicated bandwidth, controlled jitter and latency. 


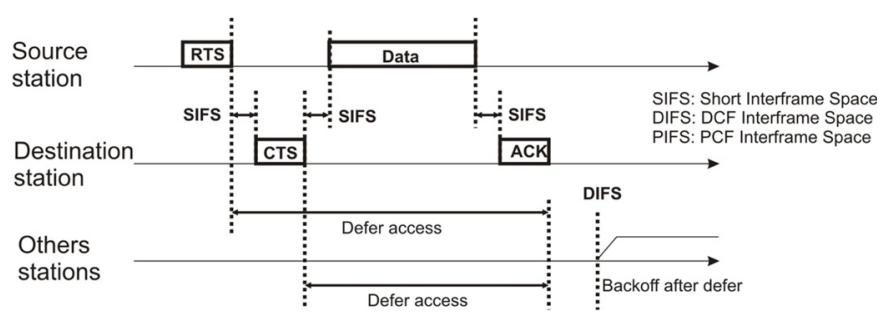

Fig. 1. Distributed coordination function DCF.

\subsection{Distributed coordination function DCF}

DCF implements the carrier sense multiple access with collision avoidance (CSMA/CA) algorithm with binary exponential backoff algorithm for accessing the medium. Carrier sensing is done through physical and virtual mechanisms. A station senses the medium to check if another station is transmitting in the physical mechanism. The virtual carrier-sense is done by distributing reservation information with RTS/CTS mechanism.

DCF includes random backoff mechanism to ensure low collision probability. This mechanism provides best effort type of service for transfer of data. DCF uses either two-way handshaking or four-way handshaking technique Chile transmitting the data. While two-way handshaking uses explicit acknowledgement (ACK) for receipt confirmation, RTS and CTS frames are used by four-way handshaking technique [4].

DCF is the basic medium access mechanism for both ad-hoc and infrastructure modes. In DCF mode, a station should ensure that the medium is free before it starts transmitting data over the channel. In the case of a busy channel, the node has to wait until the transmission by other node is complete [4]. In addition, the node has to wait for another amount of time to provide sufficient gap between subsequent frame transmissions.

There are two basic rules that need to be followed by every sensor node operating in the DCF mode. Firstly every station that has data to transmit should confirm that the channel was idle for at least DIFS (Distributed Inter-Frame Space) amount of time. Secondly, it should wait a random amount of time when it has another datagram to transmit after a successful transmission or it has a datagram to transmit but it was denied channel access, as channel was busy (Fig. 1). Each time the carrier sense operation detects the medium to be idle, the backoff timer decrements the backoff time. After the collision detect transmitter retransmits the data.

When a sensor station receives a data frame, it waits for a SIFS (Short IFS) duration and transmits an ACK to the sender. There is no carrier sensing or backing off for ACK frames. The transmitter expects an acknowledgement within SIFS time frame. Only after receiving an ACK frame correctly, the transmitter assumes that the data frame was delivered successfully. The SIFS and DIFS time frames enable the communicating pairs to complete the frame exchange sequence without collision.

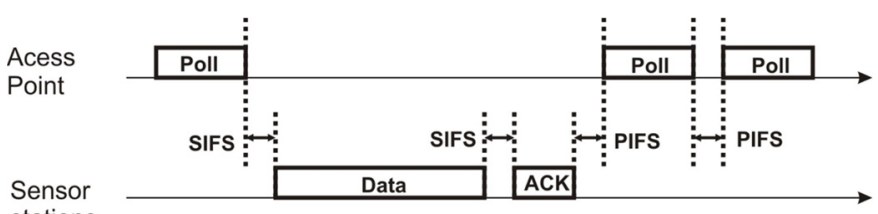

Fig. 2. Point Coordination Function PCF.

\subsection{Point coordination function PCF}

Point coordination function (PCF) is a centralized, polling-based access mechanism which requires the presence of an AP that acts as Point Coordinator (PC). In the PCF mode, time is divided into superframes. Each superframe consists of a contention period where DCF is used and a contention-free period (CFP) where PCF is used. The CFP is started by a beacon frame sent by the $\mathrm{PC}$ using DCF. The CFP may vary from superframe to superframe, as the base station has to contend for the medium. Once the CFP starts, the PC polls each station in its polling list (the high priority stations) when they can access the medium. To ensure that no DCF stations are able to interrupt this mode of operation, the inter frame space between PCF data frames (PIFS) is shorter than the DIFS.

To start the CFP, PC gains the control of the medium by waiting PIFS period of time and then sends a beacon frame (Fig. 2). It is a control frame that has all the attributes used in the CFP period. Point Coordinator builds a polling list of all the PCF enabled nodes. This list is organized according to the nodes MAC addresses. Upon receiving CFP, stations wait for SIFS period of time and then either respond with data frame along with the acknowledgement of data received or if they don't have any data to send then they will send a null frame in order to release the medium. This way $\mathrm{PC}$ will not wait for the PCF sensor stations that don't have any data to send. After waiting for SIFS period, if $\mathrm{PC}$ does not receive the data or null frame then it will repeat the polling of the same node. It keeps repeating this until maximum number of poll failures occurs. It then drops that node in that CFP period and moves to the next station [4].

The PCF has not been studied as much as the DCF. Existing studies of PCF have concentrated on the ability of the PCF mode to service real time audio traffic and on improving its efficiency using new polling mechanisms. This is because sequential polling wastes bandwidth and causes increased delays when the network is lightly loaded.

\section{Simulations and simulation set up}

To compare DCF and PCF mechanisms in wireless sensing networks (usually small amounts of data transmitted in fixed time intervals) the simulations were done in modern packed called OPNET Modeler. The simulations were done for two different networks. One of them is small point-to-point network and the second consists of couple of elements. This shows main differences between transmissions in such a networks. 


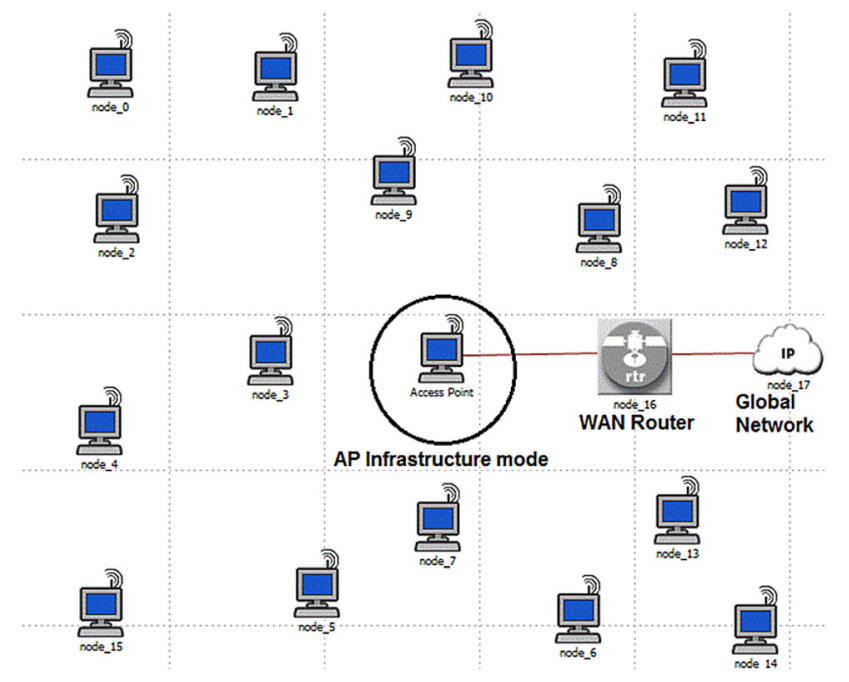

Fig. 3. Simulated system.

\subsection{OPNET Modeler environment}

In this research, the performance of DCF and PCF channel access methods were compared with respect to their support for real-time (measured data) traffic [5]. The research was carried out using a specialized software environment - OPNET Modeler network simulator. Modeler is one of the most widely used network simulators in both academic and industrial communities. It supports most of the networking protocols, including wireless protocols. PCF and DCF modules are included in the basic OPNET as part of its wireless. OPNET Modeler can be used also for simulation of modern measurement systems $[6,7]$.

An important parameter of modern distributed systems is technology used to exchange information between elements. Industry and industry control - measuring here imposes additional constraints due to the expected reliability and indivisibility of data and transmission security. Development in this area has come from wire technology, the wireless systems of a fixed network topology, and wireless systems currently being developed or an ad-hoc basis with a certain capacity for self-organization [8].

One of the impulses causing the increased interest in wireless solutions in data is the development of flexible manufacturing systems. There is the possibility of rapid reconfiguration, such as on the production line. In addition, wireless systems, by eliminating the cables are clearly less expensive: both in terms of installation and in maintenance.

Despite many advantages, wireless systems are not free of defects, which could include longer delays (time to access node) or the increased likelihood of data loss (interference from other systems operating in the band, multichanneling, work on the border of the range). It should be noted that these deficiencies can be compensated for by the appropriate choice of technology, data transmission and appropriate design of the system. OPNET allows the simulation of distributed measurement systems based on the standard simulation of WLAN with QoS.

\begin{tabular}{|c|c|}
\hline Attribute & Value \\
\hline name & node_8 \\
\hline Destination Address & 0 \\
\hline$\Xi$ Traffic Generation Parameters & $(\ldots)$ \\
\hline Start Time (seconds) & constant (2) \\
\hline ON State Time (seconds) & exponential (4) \\
\hline OFF State Time (seconds) & exponential (4) \\
\hline$\boxplus$ Packet Generation Arguments & $(\ldots)$ \\
\hline .. Stop Time (seconds) & Never \\
\hline - Traffic Type of Service & Best Effort $(0)$ \\
\hline
\end{tabular}

Fig. 4. Traffic generation parameters for node 1.

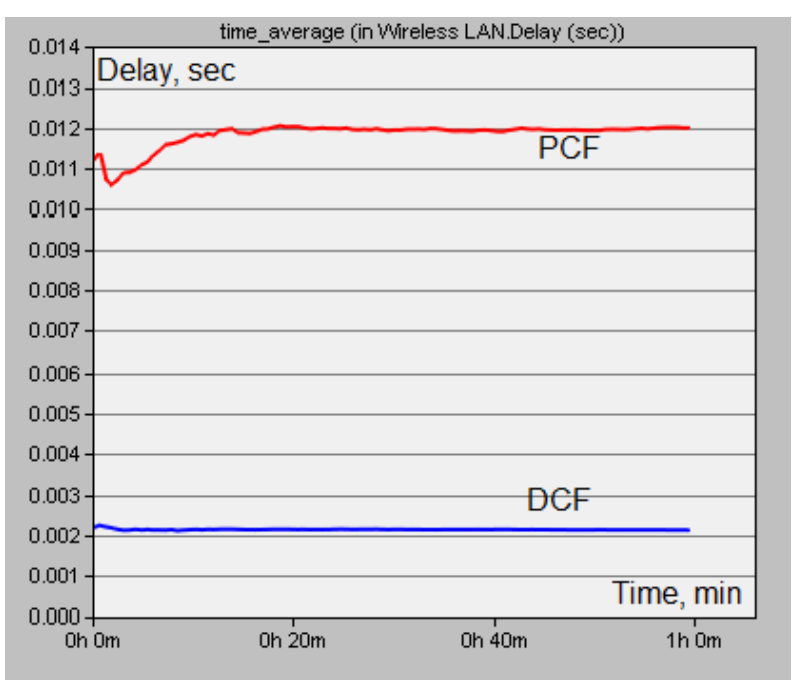

Fig. 5. Delay of packets for $50 \mathrm{~m}$.

\subsection{Simulation system}

The simulated system consisted of fifty stations and Access Point. Part of this system was shown in Figure 4. Access Point transmits received data to WAN router and next they are transmitted through the Internet. Such system can be used in AMR and AMI systems for remote meter reading.

For each station the parameters defining the generation of network traffic was set. These parameters included the time when the packets started and stopped generating and also the duration of the broadcast transmission. The start time which specified the distribution name and arguments used for generating the random start time across different nodes was constant and set to $2 \mathrm{~s}$ (Fig. 5).

'ON State Time' specifies the distribution name and arguments to be used for generating random outcomes for time spent in the 'ON' state. Packets are generated only in the 'ON' state. The 'OFF State Time' was the distribution name and arguments used for generating random outcomes for time spent in the 'OFF' state. No packets are generated in the 'OFF' state [9]. Baud rate was fixed at 11 Mbps. 


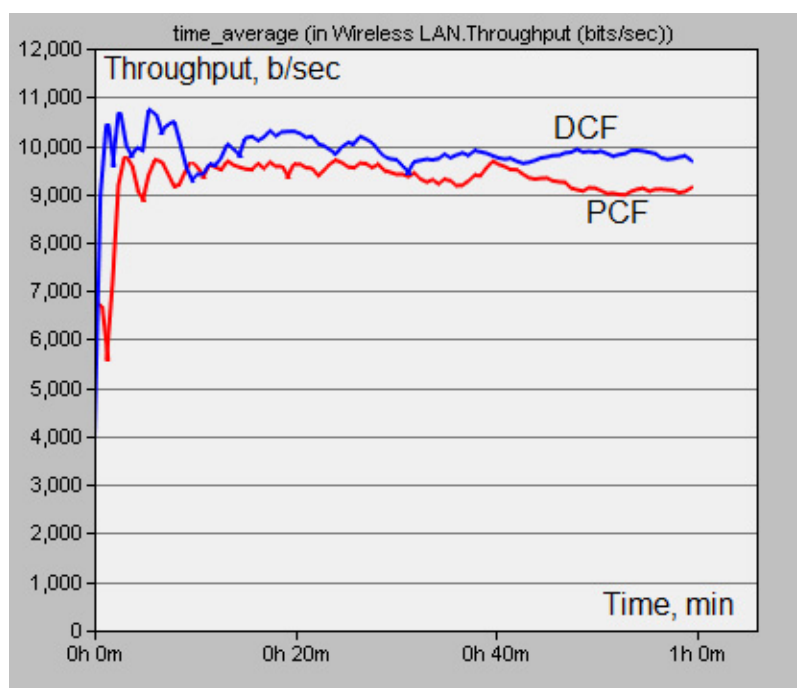

Fig. 6. Throughput in bits/sec of packets for $50 \mathrm{~m}$.

'Load' in this measurement system which represents the total load (in bits/s) submitted to wireless LAN layers by all higher layers in all WLAN nodes of the net-work is shown in Figure 6. The load is almost identical for all scenarios.

All stations were placed about $500 \mathrm{~m}$ from a central point and then the distance was increased to $1 \mathrm{~km}$. As before, both DCF and PCF mechanisms were simulated. The load was the same as previously.

The distance between the stations and Access Point was not the same. Distance from the axis of the network was increased. Each node has its own station address in order to identify itself and direct the transmission of packets. Packets were sent randomly.

\section{Simulation results}

From Figure 5 it is clear that PCF mechanism affects the packet delay much more than DCF function. The delay in simulated network is 6 times larger in PCF network.

Figure 6 shows the throughput obtained in both networks with DCF and PCF algorithms. The throughput is nearly the same in both of them.

The following graphs: Figures 7 and 8 presents the packet delay using the mechanism of PCF and DCF for a average distance of 50, 150 and $250 \mathrm{~m}$. The delay is higher using the mechanism of the central access point. At $250 \mathrm{~m}$, the number of very large packet delays increased. At this distance, the mechanism used to ensure transmission quality does not play a role in terms of packet delay time.

However, differences between the mechanisms of PCF and DCF can be seen by comparing the number of packet retransmissions, especially at large distances where the packets may be lost during transmission.

The number of retransmitted packets is greater than the distributed transmission mechanism DCF, while using the mechanism of PCF, not such a large amount of data, was lost so it is not necessary to re-send to the Access

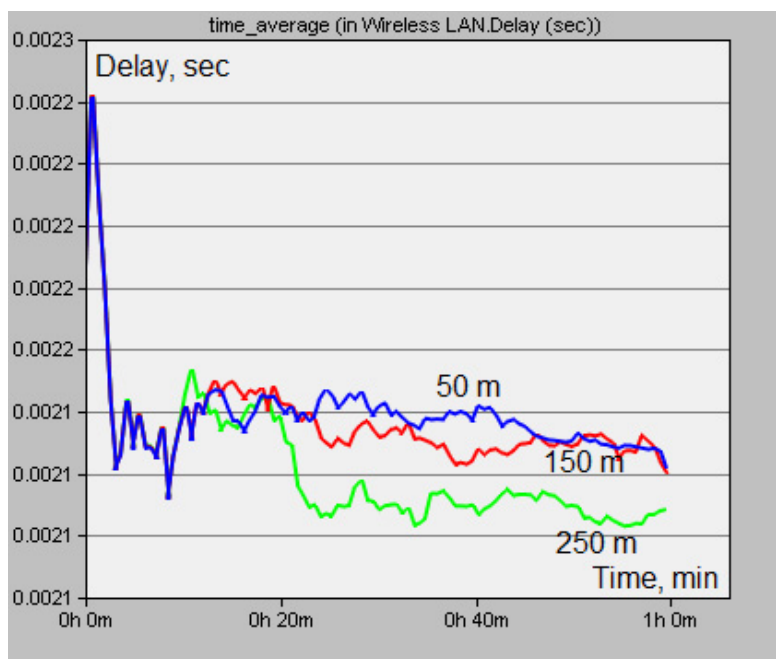

Fig. 7. Delay vs. node distance for DCF algorithm.

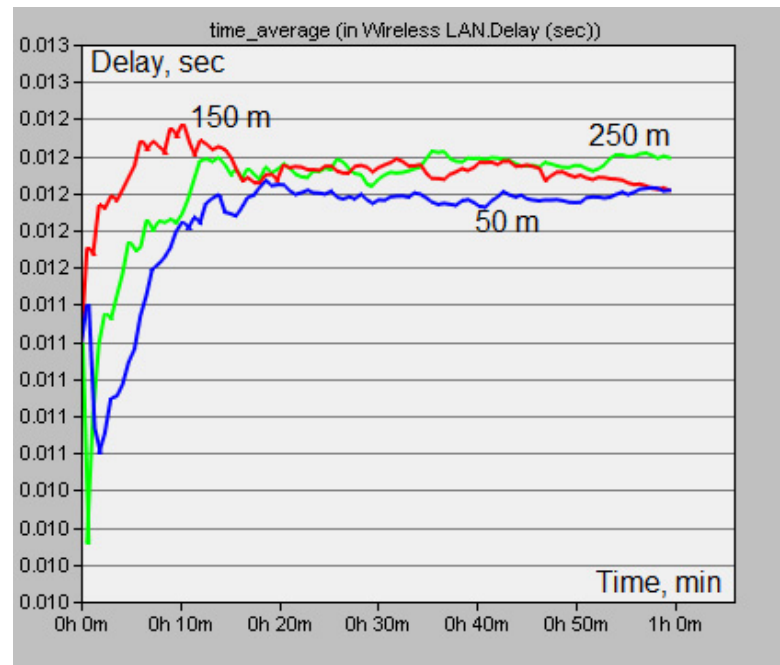

Fig. 8. Delay vs. node distance for PCF algorithm.

Point. The mechanism of PCF was used over long distances between sensors or transmitters, where the power is low.

\section{Conclusions}

This paper describes the main ways of ensuring the transmission quality measurement in wireless networks. Special attention was paid to the mechanisms of the distributed data transmission with the DCF and highlighted the central point in the network PCF. WLAN working under DCF mode suffers from high latency value when the traffic offered to the network exceeds certain limits (depending on the network size and the load demands of its clients) because of the contention nature of this mode. On the other hand, PCF mode offers higher degree of determinism to the network clients but suffers from the negative effect of polling overhead in the case of low load conditions. The wise selection of PCF parameters must takes into consideration several aspects such as the load 
Beata Krupanek and Ryszard Bogacz: OPNET Modeler simulations of performance for multi nodes wireless system1\$5-p5

expected to/from the nodes, number of nodes and the level of service provided for sensing networks requirements.

Enabling PCF functionality should be done after good study of the whole network and the total estimated load on every access point, as it may affect overall performance badly. Estimating traffic load over an AP will help to determine number of PCF stations per access point without affecting the overall performance of the network. Correctly setting number of PCF station will tune the performance of those nodes as well as overall network performance.

\section{References}

1. T. Topór-Kamiński, B. Krupanek, J. Homa, Delays models of measurement and control data transmission network, in Advanced technologies for intelligent systems of national border security, Studies in Computational Intelligence, Vol. 440 (Springer, 2013), pp. 257-279

2. L. Chandran-Wadia, S. Mahajan, S. Iyer, Throughput performance of the distributed and point coordination functions of an IEEE 802.11 wireless LAN, in ICCC'02 Proc. of the 15th Int. Conf. on Computer Communication, 2002, p. 36-49.
3. J. Fitzgerald, A. Dennis, OPNET Lab Manual, OPNET Technologies (Inc. 2009)

4. S.A. Rasheed, K. Masnoon, N. Thanthry, R. Pendse, PCF vs. DCF: a performance comparison (Department of Electrical and Computer Engineering Wichita State University, IEEE, 2007)

5. I.P. Kurytnik, M. Karpiński, Bezprzewodowa transmisja informacji (Wydawnictwo PAK, Warszawa, 2008)

6. B. Krupanek, R. Topór-Kamiński, Wykorzystanie środowiska OPNET Modeler w symulacjach sieci komputerowych, Metrologia dziś i jutro, materiały konferencyjne (MKM, Gdańsk, 2009)

7. B. Krupanek, Badania symulacyjne bezprzewodowego systemu eksperymentalnego opartego na standardzie ZigBee przy wykorzystaniu środowiska (Opnet Modeler; Monografia XI Miêdzynarodowych Warsztatów Doktoranckich OWD, 2009)

8. T. Topór-Kamiński, B. Krupanek, Niezawodność przesytu danych w rozproszonych systemach pomiarowych (Pomiary Automatyka Kontrola 10/2009)

9. www.opnet.com/university_program/teaching_with_ opnet/textbooks_and_materials/materials/OPNET_ Modeler_Manual.pdf 